Article

\title{
Assessing the Locomotor and Object Control Skill Levels of Basic Pupils in Ghana: The Role of Physical Education
}

\author{
Ernest Tsikata ${ }^{1,}{ }^{*}$, Charlotte Adomah Diaboh ${ }^{2}$, Annette Eugenia Ama Aboagye ${ }^{3}$ \\ ${ }^{1}$ Department of science, Offinso College of Education, Offinso, Ghana \\ 2 Department of science, Komenda College of Education, Komenda, Ghana \\ ${ }^{3}$ Department of Physical Education, Ghana Education Office Agotime/Ziope District Education Directorate, \\ Ghana \\ * Correspondence: bordohlity@yahoo.co.uk
}

How to cite this paper: Tsikata, E., Adomah Diaboh, C., \& Eugenia Ama Aboagye, A. (2021). Assessing the Locomotor and Object Control Skill Levels of Basic Pupils in Ghana: The Role of Physical Education. Universal Journal of Sport Sciences, 1(1), 19-27. Retrieved from https://www.scipublications.com/jou rnal/index.php/ujss/article/view/115

Received: August 20, 2021 Accepted: October 11, 2021 Published: October 13, 2021

Copyright: () 2021 by the authors. Submitted for possible open access publication under the terms and conditions of the Creative Commons Attribution (CC BY) license (http://creativecommons.org/licenses /by/4.0/).

\begin{abstract}
The study employed a quasi- experimental design of a single group pre-test post-test. The purpose of the study was to assess the locomotor and object control skill development levels of 6-8year-old basic school pupils in Kwahu Afram Plains South district of Ghana The target population for the study comprised all 6-8 years old primary school pupils in Tease in Kwahu Afram Plains in the Eastern Region of Ghana. Convenient and stratified sampling techniques were used to select 57 pupils made up of thirty-seven (37) boys and twenty (20) girls. The instrument used for this study was Test of Gross Motor development (TGMD-2). Descriptive frequencies were used to analyse the data. The study revealed that pupils demonstrated high level of perfection with reference to their locomotor skills in the various physical activities with most responses on their skill execution mostly ranked between often and always. The study also indicated that pupils were able to perform locomotor skill activities well. The study also concluded that pupils were not really equipped with motor skill and were not able to execute motor skill activities correctly during physical activities with responses on motor skill mostly ranked between rarely and often. It is recommended that lower and upper primary school teachers in Kwahu Afram Plains South district should be equipped with the prerequisite skills to enable them to teach motor skills development effectively. It is also recommended that more qualified physical education personnel should be sent to the basic level in Kwahu Afram Plains South district to teach physical education since motor development and skill acquisition develop the habit of the active lifestyle of individuals.
\end{abstract}

Keywords: Locomotor, Object Control Skill Levels, Physical Education, Kwahu Afram Plains, Ghana

\section{Introduction}

Physical education as a subject has developed from simple drills to varied patterns of activities aimed at improving the physical well-being of individuals and communities. The health benefits of a physically active lifestyle are well documented. They include improved cardiorespiratory and muscular fitness, bone and cardiometabolic health, and positive effects on weight status [1]. Current evidence suggests that many of those health benefits carry forward into adulthood [2]. Worldwide, 1 in 4 adults, and 3 in 4 adolescents (aged 11-17 years), do not currently meet the global recommendations for physical activity set [2].

Previous studies showed a global prevalence of insufficient physical activity among children aged 6-8. Initial data collected from Canada and Australia showed that less than $15 \%$ of pre-schoolers meet all three of the movement guidelines: (i) at least 180 minutes of physical activity, of which at least 60 minutes is energetic play, (ii) no more than 1 hour 
of sedentary screen time, and iii) 10 to 13 hours of good quality sleep) [3,4]. This increases their risk for poorer health and developmental outcomes and potentially poorer human capital development among nations [4-6]. As nations develop economically, levels of physical activity decreases [7]. This is a public health issue that can be addressed through physical and health education.

Policies that promote walking, cycling, sport, active recreation and play can contribute directly to achieving many of the 2030 Sustainable Development Goals (SDGs). Policy actions on physical and health education have several health, social and economic benefits, and directly contribute to achieving SDG3 (good health and well-being), as well as other goals including SDG2 (ending all forms of malnutrition). Physical education for kids is to help develop their fundamental motor skills and refine their movement. Physical education improves the general health of the individual community, leading to lower absenteeism from school [7]. The most important purpose of physical education at the kids' level is the development of mechanical efficiency, i.e. coordination, awareness, relationships and skills characterized by the use of large muscles in vigorous activities featuring manipulative, locomotor and non-locomotor skills. The keywords at this level are play and fun [8].

One way of realising the purpose of physical education is through motor development. Motor development refers to the development of a child's bones, muscles and ability to move around and manipulate objects in his or her environment. Motor development can be divided into two sections: gross motor development and fine motor development. Motor skill development is composed of locomotor skills and object control skills. Locomotor skills involve moving the body through space and include skills such as running, galloping, skipping, hopping, sliding, leaping, whiles object control skills involve catching, striking, kicking and dribbling [9].

Fundamental motor skills are categorized into two groups, listed as locomotor skills and object control skills [10]. Locomotor skills are motor skills that children perform to move from one point to another point in the physical environment. For example, locomotor skills are walking, running, jumping, leaping, skipping, galloping and hopping (http://fundamentalmovementskills.weebly.com). Object control skills include throwing, catching, striking, kicking, rolling and dribbling and are motor skills in which a child manipulates an object (e.g. ball or a bean bag) by hands, and/or feet [11]. Both locomotor and object control skills are vital to normal motor functioning. A study found out that development at the early stage of life is a rapid one. For this reason, the process of change is observable in motor behaviours in the early years of growth and maturation [9]. During the early years of children, the mastery of gross motor skills is necessary for progression into more complex games, physical activities and sport form [12].

The Early Childhood (defined as ages 6-8) is arguably a critical period in life for developing important physical, motor, social and cognitive skills. It is a critical time for the development of fundamental motor skills, this stage is considered being a responsive learning period which helps children in harmonious future development and acquisition of movement skills to enable them to execute tasks with precision without difficulty. This can be achieved through basic fundamental motor skills such as kicking, striking, hopping, jumping, sliding, gliding, throwing and catching. If these skills (psychomotor) are not acquired at the early stages of development (6-8) years, it then tends to have a negative effect on individuals in their quest to execute movement and other related skills in the future [13].

Apart from classroom teaching, teachers have a role of supervising pupils' play and other physical activities they undergo throughout instructional periods, but most teachers pay little or no attention during pupils' play time. This is as a result of having little or no knowledge of developmentally appropriate physical activities for kids. Historically, lower primary is a place where children meet to interact with their age mates and learn basic skills through play that focuses on nurturing children's intellectual, moral and physical 
development. Hence the mandates of the lower primary school teachers couple with the pre-exposure activities such as good tenderly care and teaching of motor skills to pave way for formal education demands call for attention to be given to kids because the period which begins (6-8 years) is considered as "golden years of motor development" [13].

However, motor skills development is considered as a building block of motor skill acquisition [14]. Also, motor skills, if not mastered in early years (6-8), kids may encounter difficulties when learning more complex skills and even not continue to pursue and progress in motor activity towards skilfulness [15]. It is for these and other reasons that access to physical education and sports is enshrined as a fundamental human right in the UNESCO charter in physical education and sports. The charter states that every human being has a fundamental right of access to physical education and sport which are essential for the full development of one's personality [15]. (www.portal.unesco.org.13/01/2018).

In Ghana, physical education and sports have been part of Ghana's education system since colonial era during the governorship of Gordon Guggisburg (1919-1927) with three of his sixteen principles stressing on the importance of Physical education and Sports teaching. Physical education teaching has been enshrined in the physical education and health documents of the National Council for Curriculum and Assessment (NaCCA). The teaching and learning of physical education is based on principles of Science, Psychology, Sociology and Movement education.

The teaching and learning of Physical education (now Physical and Health Education) in Ghana is a compulsory and Kwahu Afram Plains South District is not an exception. Kwahu Afram Plains South District is located in the Eastern Region of Ghana with a total land area of approximately 3,095 sq. $\mathrm{km}$. The District is bounded to the north by the Kwahu Afram Plains North, to the south by the Kwahu South, to the east by the Afram River and to the west by two Districts in the Ashanti region precisely Sekyere East (Sekyere Afram Plains) and Ashanti-Akim North Districts. To get to the district capital, one has to cross a three-kilometre-wide Afram River to Ekye-Amanfrom by ferry operated by the Volta Lake Transport Company (VLTC). After which one can travel by road to Tease the district capital. The inhabitants are heterogeneous though the land belongs to the Kwahus'. The dominant occupation in the district is agriculture, employing $77.4 \%$ percent of the total labour force while other job opportunities also employ $7.3 \%$ of the labour force (KAPSDA)

There are 84 public basic schools in the district with a population of 14,483 according to District Education Statistics 2017.These Schools are scattered in the various settlements. Consequently, pupils walk an average of 2kilometres from home to school. Kwahu Afram Plains is well noted for her exploit in Athletics especially hand games where they always excel at basic and second cycle level both at district and regional level. Most teachers teaching at the KG and the lower primary level are mostly sports and other recreational activities masters, but the irony aspect of this is that majority of them had no formal training on motor skill development. Therefore, this study tends to examine the influence of Kids Athletics on motor skill development level of 6-8years old pupils at the Kwahu Afram Plains South district in the Eastern Region, Ghana.

The World Health Organization (WHO) has identified preventing noncommunicable diseases among young children as one of its key priorities in the 21st Century; movement behaviours play a key role in contributing to this [2]. The Ministry of Education (MoE) and Ministry for Youth and Sports, through the Ghana Education Service (GES) and the Curriculum Research and Development Division (CRDD) now National Council for Curriculum and Assessment (NaCCA) developed and operationalized the teaching Syllabus for Physical Education and Sports (PES) since September 2006 for basic schools which includes the teaching of fundamental motor skills. The Physical Education Syllabus at the basic school level seeks to improve the general health of the individual; improve the general health of a community, leading to lower 
absenteeism from school and work; create the love for sports and games; serve as the basis for the training of potential athletes for clubs and the nation; and impart a healthy and positive attitude of mind that helps academic work in school [17].

Fundamental motor skills serve as the basis for the development of complex skills needed for playing other sports and serves as a window of opportunity to reduce health inequalities among children. Age appropriate balance and coordination allows the child to be involved in the sports participation with a reasonable degree of success as it aids fluid body movement for physical skill performance (e.g. walking a balance beam or playing football) [18]. Adequate development of these skills will enable kids to develop self-confidence to explore their environment and also go a long way to enhance cognitive and social development. Mastery of gross motor skills is necessary for progression into more complex games, physical activities and sports form [12].

Unfortunately, despite the existence of systems to enforce its implementation, the situation, though anecdotal, shows that Physical Education is still not being implemented well in schools in the district and in a few isolated cases where it is being taught, it appears the subject is not being taught effectively. The researcher who doubles as a District Physical Education Coordinator, whose primary roles are to monitor, supervise, train and coordinate physical activities in the District noticed that, most teachers in the District are compelled to increase literacy and numeracy instruction at the expense of child's play time. This has as adverse effect on enrolment, retention and learning. The purpose of the study was to assess the locomotor and object control skill development levels of 6-8-year-old basic school pupils in Kwahu Afram Plains South district of Ghana. The study was guided by this research question-what are the locomotor and object control skill levels of pupils in the Kwahu Afram Plains South District?

\section{Materials and Methods}

\subsection{Research Design}

The study employed a quasi- experimental design of a single group pre-test post-test. The group was single, of which a test was conducted on the group, a treatment was given after the test and finally another test was conducted. This design enabled the researchers to assess some selected motor skill development of 6-8years old pupils, since this design does not provide full control, it is extremely important that the researchers be aware of interpretation. This design permits one to reach reasonable conclusion even though full control is not possible [19]. Whiles a descriptive survey design was used to collect data on teachers' knowledge base on pupils' developmentally physical activities.

\subsection{Population of the Study}

The target population for the study comprised all 6-8 years old primary school pupils in Tease in Kwahu Afram Plains in the Eastern Region of Ghana. There are 84 public basic schools in the district with a population of 14,483 pupils [20].

\subsection{Sample and Sampling Technique}

A total 57 pupils made up of thirty-seven (37) boys and twenty (20) girls were selected for the study. Convenient and stratified sampling techniques were used to select the basic school pupils for the study. The pupils were identified under three strata: 6 years, 7 years and 8 years. The sampling frame of all pupils within each stratum were made available and numbers were assigned to them on pieces of paper. The slips of paper bearing names and numbers of pupils within each age group were folded one by one and put into a container and shuffled thoroughly. A selector was then asked to pick a slip of paper, one after the other, without first looking into the pool, until the required number of pupils was selected. Once a number was selected, it was recorded and set aside before a new one was picked. The container was reshuffled and another number picked, 
recorded, and set aside without replacement. The process was repeated until the required number of pupils within each stratum was obtained. Below is a breakdown of how samples were obtained. (22) 6years old comprising 12 boys and 10 girls, (15) 7 years old comprising 7 boys and 8 girls and (20) 8 years olds comprising 11 boys and 9 girls.

Convenient sampling technique was used to select 6-8 years old pupils from three (3) public primary schools in the district. Convenient sampling allows participants to be part of the study at their free will. The justification of employing stratified random sampling technique was to separate the pupils into age strata from six years to eight (6-8) and to ensure appropriate representation of the participants across the strata. The instrument used for this study was Test of Gross Motor development (TGMD-2) [12]. The test is a revised version of TGMD-2 by Ulrich, in the year1985. It is a standardized test that measures gross motor ability that develops early in life. Descriptive frequencies were used to analysed the data.

\section{Results}

The Table 1 below is the results of locomotor and object control skill levels of pupils in this study.

Table 1. Locomotor and Object control skill levels of pupils

\section{Locomotor Skills}

\begin{tabular}{|c|c|c|c|c|c|}
\hline $\mathrm{S} / \mathrm{N}$ & Item & Never & Rarely & Often & Always \\
\hline 1 & $\begin{array}{c}\text { Move arms in position to } \\
\text { leg elbow bent }\end{array}$ & $1(1.7 \%)$ & $9(15.0 \%)$ & $28(46.7 \%)$ & $22(36.7 \%)$ \\
\hline 2 & $\begin{array}{c}\text { Bend arm and lift arms to } \\
\text { waist level at take off }\end{array}$ & $1(1.7 \%)$ & $12(20.0 \%)$ & $33(55.0 \%)$ & $14(23.3 \%)$ \\
\hline 3 & $\begin{array}{l}\text { Take off on one foot and } \\
\text { land on the opposite foot }\end{array}$ & $5(5 \%)$ & $15(25 \%)$ & $26(43 \%)$ & $16(26.7 \%)$ \\
\hline 4 & $\begin{array}{c}\text { Bend arms and lift it to } \\
\text { waist level whiles } \\
\text { galloping }\end{array}$ & $2(3.4 \%)$ & $16(26.7 \%)$ & $32(53.3 \%)$ & $10(16.7 \%)$ \\
\hline 5 & $\begin{array}{l}\text { Move arms and bend } \\
\text { elbows in opposition to } \\
\text { legs whiles running }\end{array}$ & $3(5.0 \%)$ & $16(26.7 \%)$ & $26(43.3 \%)$ & $15(25.0 \%)$ \\
\hline \multicolumn{6}{|c|}{ Object control skill } \\
\hline 6 & $\begin{array}{l}\text { Contact a ball with one } \\
\text { hand about belt level }\end{array}$ & $7(11.7 \%)$ & $25(41.7 \%)$ & $16(26.7 \%)$ & $12(20.0 \%)$ \\
\hline 7 & $\begin{array}{c}\text { Push a ball repeatedly } \\
\text { downwards from waist } \\
\text { level }\end{array}$ & $9(15 \%)$ & $26(43.3 \%)$ & $21(35.0 \%)$ & $4(6.7 \%)$ \\
\hline 8 & $\begin{array}{l}\text { Catch or receive a ball } \\
\text { thrown to them }\end{array}$ & $18(30 \%)$ & $9(15 \%)$ & $9(15 \%)$ & $24(40 \%)$ \\
\hline 9 & $\begin{array}{l}\text { Extend arms whiles } \\
\text { reaching for a ball thrown } \\
\text { to them }\end{array}$ & $1(1.7 \%)$ & $11(18.3 \%)$ & $32(53.3 \%)$ & $16(26.7 \%)$ \\
\hline 10 & $\begin{array}{l}\text { Push ball with finger tips } \\
\text { without slapping }\end{array}$ & $5(8.3 \%)$ & $27(45 \%)$ & $22(36.7 \%)$ & $6(10 \%)$ \\
\hline
\end{tabular}


The following are the results of locomotor control skill level of pupils:

Item 1 shows results of a test on kids' ability to move arm and bend elbow in opposition to leg whiles running, results indicated that, never $1(1.7 \%)$, rarely $9(15.0 \%)$, often $28(46.7 \%)$ and, always $22(36.7 \%)$. The results above show that majority of pupils $28(46.7 \%)$ often move arm and bend elbows in opposition to legs while running.

Item 2 shows results of a test on pupils' ability to bend arms and lift it to waist level when asked to gallop. Results indicated that, never $1(1.7 \%)$, rarely $12(20 \%)$, often $33(55.0 \%)$ and always $14(23.3 \%)$ The results show that majority of pupils $33(55.0 \%)$ often bend arms and lift it to waist level when asked to gallop.

At this wavelength Item 3, shows results of kids' ability to take off on one foot and land on the opposite foot, results indicated, never 5(5\%)rarely $15(25 \%)$, often $26(43 \%)$, and always $16(26.7 \%)$. This indicates that majority of pupils $16(26.7 \%)$ always take off on one foot and land on opposite foot.

Item 4 shows results of pupils' ability to bend arms and lift it to waist level whiles galloping results indicated, never 2(3.4\%)rarely $16(26.7 \%)$, often $32(53.3 \%)$, and always $10(16.7 \%)$. This implies that majority of pupils often bend arms and lift it to waist level whiles galloping.

Finally, on locomotor skill control level of pupils, item 5 shows pupils ability to move arms and bend elbows in opposition to legs whiles running. Results indicates that, never $3(5.0 \%)$ rarely $16(26.7 \%)$, often $26(43.3 \%)$, and always $15(25.0 \%)$, results show that majority of pupils often move arms and bend elbows in opposition to leg whiles running.

Concerning object control skill level of pupils, the following are the results. Item 6 on pupils' ability to contact a ball with one hand about belt level shows that, never $7(11.7 \%)$ rarely $25(41.7 \%)$, often $16(26.7 \%)$, and always $12(20.0 \%)$, results of this shows that majority rarely contact a ball with one hand about belt level.

Item 7 indicates pupils' ability to push a ball repeatedly downwards from waist level, results of this shows that, never $9(15 \%)$ rarely $26(43.3 \%)$, often $21(35.0 \%)$, and always $4(6.7 \%)$, this also implies that majority of pupils rarely push a ball repeatedly downwards from waist level.

In addition, item 8 which indicates pupils' ability to catch or receive a ball thrown to them shows that, never $18(30 \%)$ rarely $9(15 \%)$, often $9(15 \%)$, and always $24(40 \%)$, this implies that majority of pupils $24(40 \%)$ always catch or receive a ball thrown to them.

Item 9 further states pupils' ability to extend arms while reaching for a ball thrown to them. Results show that, never $1(1.7 \%)$ rarely $11(18.3 \%)$ often $32(53.3 \%)$, and always $16(26.7 \%)$ this implies that, majority of pupils often extend arms whiles reaching for a ball thrown to them. Finally, on objects control skill level of pupils, item 10 on results shows that pupils ability to push ball with finger tips indicates never 5(8.3\%)rarely $27(45 \%)$ often $22(36.7 \%)$, and always $6(10 \%)$. This implies that majority of pupils $27(45 \%)$ rarely pushball with finger tips without slapping it when ask to.

\section{Discussions}

The results on the research question show that, on locomotor test of kids, majority $26(43.3 \%)$ of kids are able to move arm and bend elbow in opposition to legs whiles running, minority $3(5.0 \%)$ of kids are not able to move and bend their arm in opposition whiles running. According to Kid central.com. at the age of 6-8 these are some of the activities that kids can perform, refined coordination of large and small muscles coupled with refined hand-eye coordination, able to draw and write with greater control and precision, move in time to the beat or rhythm of music and ride a two-wheel bike as well as learn important swimming skills. In addition, kids have better balance and coordination, refine skills of climbing, running, skipping, hopping and tumbling and finally learn sports involving good physical control [21]. 
The findings of this study agree with a similar research which posit that doctrine of specificity is the identification of the extent of specificity of tasks of motor ability [22]. The idea of generalization is directly or indirectly harmful to the objectives of the task development and solution. Generality, as far as motor abilities are concerned, is not proper. This is so because; there are individual tasks with specific goals that affect different individual subjects with varying degrees of individual differences. Therefore, calls for a specific approach to specific tasks. It means a good understanding of the problems, the tasks and the most appropriate test batteries for the solution to the task. For example, if the problem involves leg movement, the task and its objectives must involve the movement of the leg and, consequently, the test batteries should involve leg movement. Nonetheless, certain tasks call for use of not only one body part but two or more. This demands a good knowledge and understanding of the task so that the test when executed will specifically address the task resulting in the achievement of the objective. Some of the problems seem closely related, thus posing problems to young researchers and investigators in their task development in line with the doctrine of specificity. Notwithstanding, the close relation of two motor activities, apparently the individual differences tend to separate them. For example, individual differences involvement time. The ability to run or move fast does not depend on the ability to react fast.

Furthermore, results of this study indicated that, majority of Kids $n=36(60.0 \%)$ are able to catch or received ball thrown to them whiles minority $24(40.0 \%)$ of the kids are not able to catch or received a ball thrown to them. The findings of this study agree that transfer of learning can facilitate the learning of motor skills [23]. The influence exerted may be positive or negative. When a previous experience or skill aids in the learning of a new skill, positive transfer occurs. For example, the student who knows how to play tennis readily learns how to play badminton because both skills require similar strokes and the use of a racket. Most researchers agree that positive transfer most likely occurs when two tasks have similar part-whole relationships. Transfer, however, is not automatic The researchers can infer that, based on field data collected on teachers' knowledge base on developmentally appropriate physical activities of pupils in the district, most teachers in the district are not having the requisite basic knowledge of teaching pupils age 6-8 years old, hence pupils are unable to perform motor skills with precision.

This finding is in line with previous studies that, differences existed between motor skills performance and that correlation exists between object control and locomotor skills [23]. gross motor skills were significant predictors of adaptive behaviour in daily living skills among children [24]. Researchers opine that a strong relationship existed between gross motor skills and there is a large age effect [25]. The results of the finding further agree that there is a significant relationship that existed between locomotor skills and object control skills such as running, galloping, spring and jump [26]. However, a similar study supported this current finding that, higher proportion of kids found within the highest socioeconomic setting displayed proficient running skills whiles kids in the middle setting showed advanced skills in both locomotor and object control skills [27].

\section{Conclusions}

The study revealed that pupils demonstrated high level of perfection with reference to their locomotor skills in the various physical activities with most responses on their skill execution mostly ranked between often and always. The study also indicated that pupils were able to perform locomotor skill activities well. Also concluded that pupils were not really equipped with motor skill and were not able execute motor skill activities correctly during physical activities with responses on motor skill mostly ranked between rarely and often. This showed that, the motor skill level of the pupils is low as compared to locomotor skills. 


\title{
Recommendations
}

It is recommended that lower and upper primary school teachers in Kwahu Afram Plains South district should be equipped with the prerequisite skills to enable them teach motor skills development effectively. It is also recommended that, Parents in Kwahu Afram Plains South District should encourage their kids, especially 6-8 years old, to participate often in physical activities to develop their motor skills for life long living. It is recommended that more qualified physical education personnel should be sent to the basic level in Kwahu Afram Plains South district to teach physical education since motor development and skill acquisition develop the habit of active lifestyle of individuals.

\begin{abstract}
Author Contributions: Conceptualization ET; methodology, ET; validation, ET, CAD, and AEAA; formal analysis, ET and CAD; investigation, ET, CAD, and AEAA; resources, A. K. O.; data curation, ET, CAD, and AEAA; writing-original draft preparation, ET and CAD; writing-review and editing, ET.; visualization, ET, CAD, and AEAA; supervision, ET.; project administration, ET, CAD, and AEAA. All authors have read and agreed to the published version of the manuscript.
\end{abstract}

Funding: "This research received no external funding"

Data Availability Statement: Data is available on request from the corresponding author.

Acknowledgments: we acknowledge the Dr. Anthony Bordoh for his input and suggestions

Conflicts of Interest: "The authors declare no conflict of interest." "No funders had any role in the design of the study; in the collection, analyses, or interpretation of data; in the writing of the manuscript, or in the decision to publish the results".

\section{References}

[1] Physical Activity Guidelines Advisory Committee (2008). Physical Activity Guidelines Advisory Committee Report, 2008. Washington, DC: U.S. Department of Health and Human Services.

[2] WHO (2016). Global Reference List of 100 Core Health Indicators. Geneva: World Health Organization.

[3] Cliff, D. P., McNeill, J., \& Howard, S. (2017). Adherence to 24-Hour movement guidelines for the early years (ages 0-4) and associations with social cognitive development among pre-school children from Wollongong, Australia BMC Public Health; in press.

[4] Chaput, J. P., Colley, R., \& Janssen, I. (2017). Proportion of preschool-aged children meeting the Canadian 24-Hour Movement Guidelines for the Early Years and associations with adiposity: Results from the Canadian Health Measures Survey. BMC Public Health. 2017; in press.

[5] Carson, V., Lee, E-Y., \& Hewitt, L. (2017). Systematic review of the relationships between physical activity and health indicators $\mathrm{i}$ in the early years (aged 0-4 years). BMC Public Health. 2017; in press.

[6] Black, M. M., Walker, S. P., \& Fernald, L. C. H. (2017). Early childhood development coming of age: science through the life course. The Lancet. 389(10064), 77-90.

[7] World Health Organization (2016). Report of the commission on ending childhood obesity. Geneva, Switzerland.

[8] CRDD (2010). Physical Education Teaching Syllabus for Primary Schools. Ministry of education.

[9] Haywood, K., \& Getchell, N. (2010). Life span motor development. Windsor, Ontario, Canada: Human Kinetics.

[10] Humeric, I. (2010). The effects of two motor skill Interventions on Preschool Children's object control skills and their perceived motor competence Unpublished doctoral dissertation, The Ohio State University, Columbus, OH. http://fundamentalmovementskills.weebly.com.

[11] Ulrich, D. A. (2000). The test of gross motor development ( $2^{\text {nd }}$ ed.). Texas: Pro-ed. USA.

[12] Malhotra, S. (2009). Incidence of childhood psychiatric disorder in India. New Delhi: Sage.

[13] Barela, J. A. (2017). Adapted physical activity in promoting infant motor development Sobama. Behavior, 3, 249-255.

[14] Clark, J. E. (2007). Class and sports activities in kindergarten and elementary school: Perceptual cognition and action. Cambridge, M.A: MIT Press

[15] UNESCO. 2011. MIL Curriculum for Teacher Education. Paris: UNESCO. 
[16] National Council for Curriculum and Assessment (NaCCA) (2018). Teaching Syllabus for Physical Education and Sports (PES). Ministry of Education (MoE) and Ministry for Youth and Sports

[17] Buttfield, S. A., Angel R.M, \& Lovies, E. M. (2012). Age and sex differenciesin object control skills by children age 5-14. Perceptual and Motor Skills, 114(1), 261-274.

[18] Campbell, D. T., \& Stanley, J. C. (1966). Experiental and quasi-experiental design for research. Chicago: Rand McNally \& Company

[19] Ghana Statistical Service (2018). Tracking Progress in Ghana's Basic Level Education across Districts 2010 - 2016. Retrieve online $23 / 4 / 2018$

[20] Department of Health. (2011). Start active, stay active.: Report on physical activity in the UK. Retrieved from https://www.gov.uk/government/uploads/system/uploads/attachment_data/file/216370/dh_128210.pdf

[21] Pufaa, H. A. (2006). Motor learning in Physical Education and sport. Tema: Kobi's Press Ltd.

[22] Pfeiffer, K. A., McIver, K. L., Dowda, M., Almeida, M. J., Pate, R. R. (2008). Validation and calibration of the Actical accelerometer in preschool children. Medicine and Science in Sports and Exercise, 38, 152-157

[23] Ulrich, D. A., \& Lord, C. (2015). The relationship of motor skills and social communicative skills in school-aged children with autism spectrum disorder Pro-Ed Publisher.

[24] Holt, R. J., Willkie, R. M., \& Mon-Williams, M. (2014.) The relationship between a child's postural stability and manual dexterity

[25] Fatemeh, S. H., Peyrovi, A., \& Isavi, R. (2015). Comparing the growth of fitness and health: international proceedings and consensus statement.

[26] Veldman, S. L., Jones, R. A., \& Okely, A. D. (2016). Efficacy of gross motor skill interventions in young children: an updated systematic review. BMJ Open Sport Exercise Med, 2, e000067. 